\title{
Mesenchymal chondrosarcoma of the orbit
}

\author{
DAVID SEVEL
}

From the Department of Ophthalmology, Groote Schuur Hospital, and the University of Cape Town, South Africa

The histological features of mesenchymal chondrosarcoma, first described by Lichtenstein and Bernstein (1959), consist of primitive undifferentiated mesenchymal cells in which islands of cartilage are noted.

To date, 65 cases of mesenchymal chondrosarcoma have been described, 67 per cent. occurred in bone and 33 per cent. were extraskeletal (Guccion, Font, Enzinger, and Zimmerman, I973).

Six mesenchymal chondrosarcomata have been described in the orbit (Salvador, Beabout, and Dahlin, r964; Reeh, r966; Trzcinska-Dabrowska, Witwicki, and Zielinska, ı969; Cárdenas-Ramírez, Albores-Saavedra, and de Buen, 197I; Guccion and others, I973).

\section{Case report}

A 19-year-old Negro female was admitted to Frere Hospital, East London, South Africa, on February 22, 1968, with a 3-week history of pain over the right eye followed by "swelling".

Ophthalmoscopical examination showed marked proptosis of the right eye, which was displaced downwards and laterally by an indurated nodular mass, situated below the superior orbital margin. The tumour filled the supero-medial angle of the orbit and extended laterally.

Ocular movements were limited in all directions of gaze. The visual acuity on this side was $6 / 60$ and a marked papilloedema was noted on fundoscopy.

$X$ ray of the paranasal sinuses showed a soft tissue swelling overlying the right orbit.

The orbit was slightly enlarged and the infero-lateral aspect of the bones of the orbit could not be identified.The right maxillary antrum was opaque and the frontal sinuses showed no abnormality.

Detailed examination of the left eye and adnexa showed no abnormality.

On March I, 1968, a biopsy of the mass was taken.

\section{Histological examination}

The specimen consisted of small fragments of tissue up to $0.5 \mathrm{~cm}$. in size.

There were two distinctive components to the neoplasm one cartilagenous and the other fibrous (Fig. 1). The cartilage was lobular in outline and was undergoing calcification. The fibrous component of the tumour consisted of cellular areas in which the nuclei were round to oval, hyperchromatic, and tended to have a linear arrangement. There was a fasciculated pattern under low power. The capillaries were prominent within the neoplasm and in one area, which consisted mainly of fibrous tissue, there was a capillary from which neoplastic cells ran at right angles to the vessel.

After the biopsy, the mass rapidly increased in size, caused marked proptosis, and was associated with pain. 


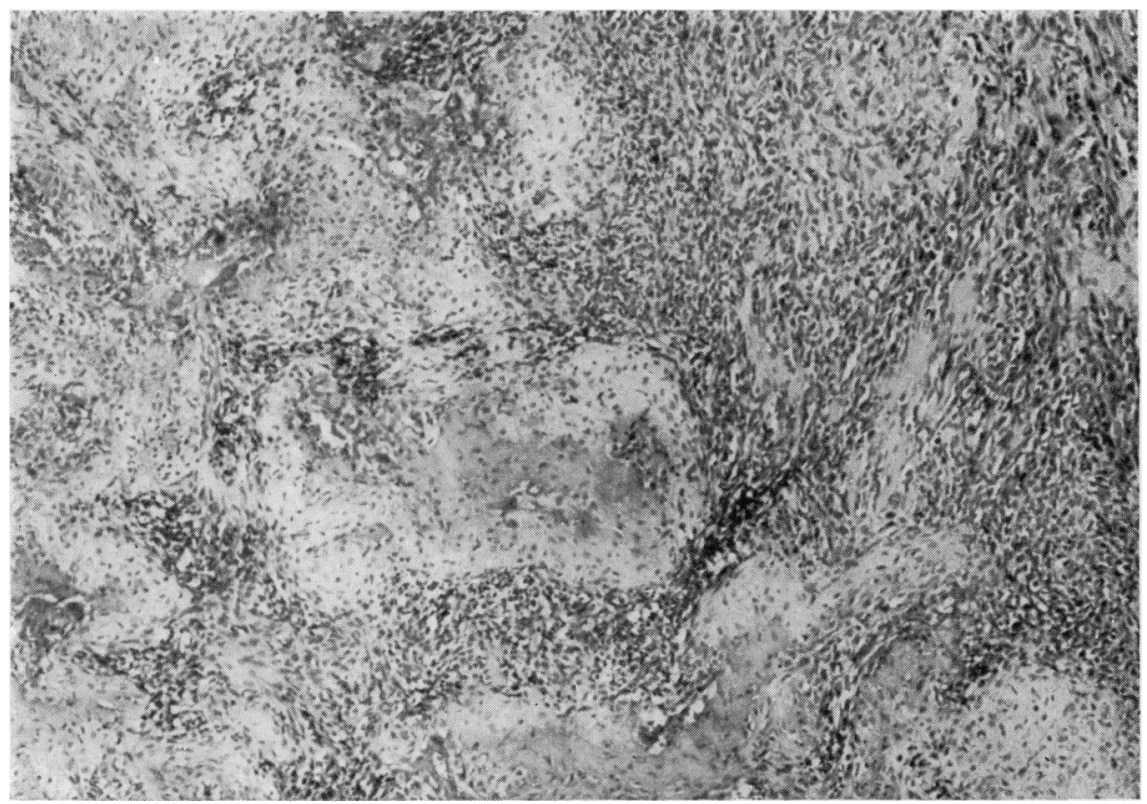

FIG.I Section shows undifferentiated mesenchymal cells and lobulated islands of cartilage. Haematoxylin and eosin. $\times 75$

The patient was referred to the Eye Department at Groote Schuur Hospital, South Africa, on March I I, 1968.

\section{Ophthalmic examination}

The right eye was grossly proptosed in a downwards and outwards position (40 mm.). A tender mass, which was palpated in the supero-medial aspect of the orbit, was firm and its surface smooth. The tail-end extended to the region of the lacrimal gland. There was marked chemosis, and conjunctival congestion as well as eversion of the inferior fornix (Fig. 2). The cornea was hazy and there was exposure keratitis as evidenced by superficial corneal ulceration. The corneal opacification precluded a clear view of the fundus.

The preauricular and submandibular lymph nodes were not enlarged.

$X$ ray of the skull showed enlargement of the right orbit which was filled with soft tissue mass. The optic foramen and orbital fissure were obscured by the tumour.

\section{Left eye}

Examination of the left eye showed no gross abnormality. The visual acuity was $6 / 6$ and no pathology

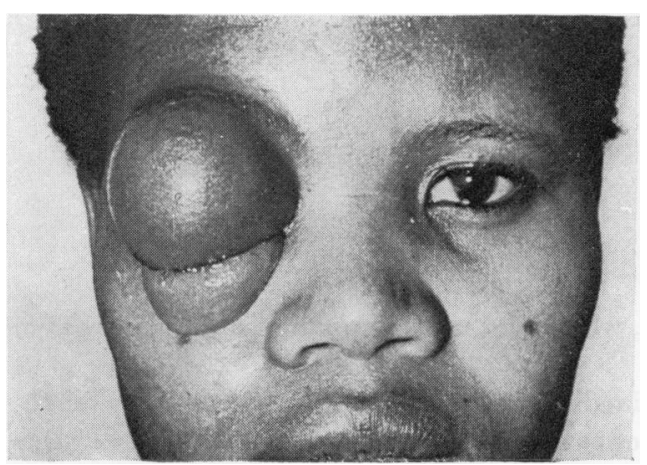

FIG. 2 Gross proptosis and eversion of the inferior fornix due to mesenchymal chondrosarcoma of orbit 
was noted in either the anterior or the posterior segment of the eye. Movements were full in all directions of gaze.

\section{Laboratory studies}

On March 19, 1968, a right carotid angiogram was done. The intracranial vessels were normal. The ophthalmic artery was dilated and abnormal tumour vessels were present along the lower aspect of the orbit (Fig. 3).

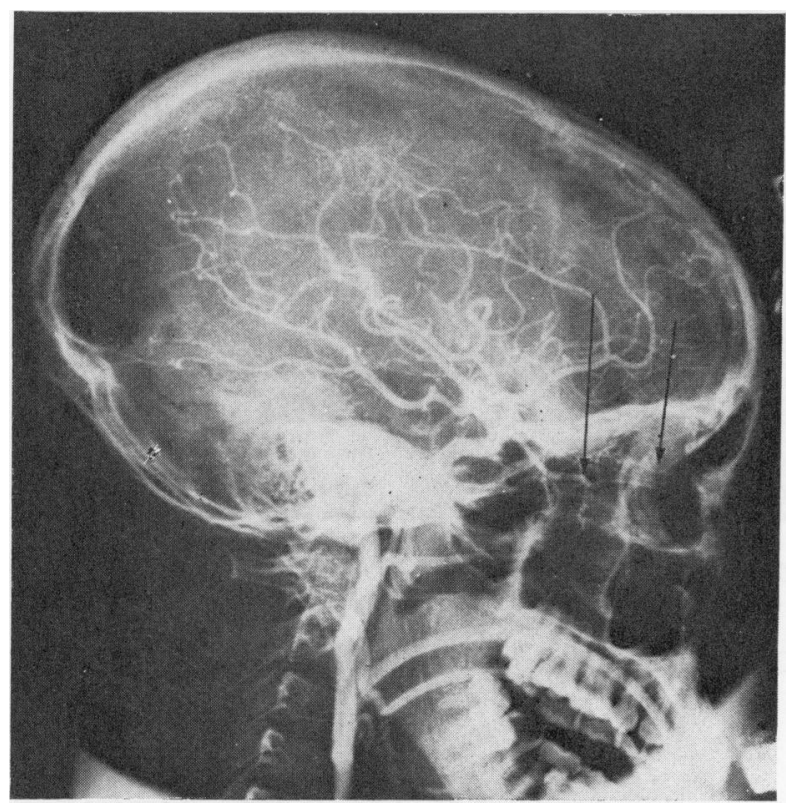

FIG. 3 Carotid angiogram shows (arrowed) marked vascularity of orbital tumour

While radioactive studies (Iodine ${ }^{131}$ ) showed an increase uptake over the right orbit, there was no increased uptake intracranially (Fig. 4).

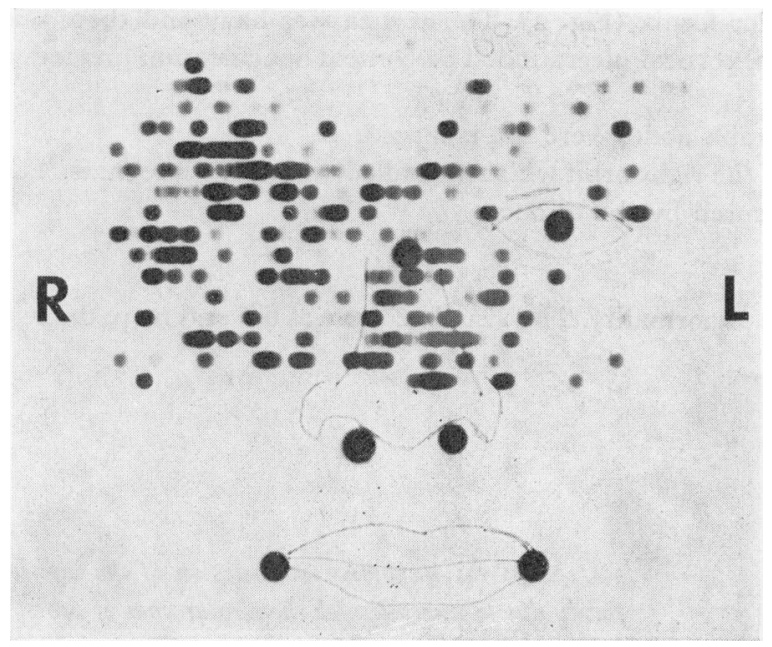

FIG. 4 Radioactive studies (Iodine ${ }^{131}$ ) shows increased uptake over the right orbit

The patient was examined by an otolaryngologist, who found no abnormality in the nasopharynx or ears.

In consultation with the radiotherapist, it was decided to treat the patient with deep $x$-ray therapy and cytotoxic therapy before surgery. Over a period of 19 days, a dose of 3,500 rads was administered 
to the orbit and in addition during this period 2,700 $\mathrm{mg}$. actinomycin $\mathrm{D}$ were given in three divided doses.

The orbital mass decreased in size and the tail-end of the tumour, which extended towards the lacrimal gland, was not palpable. There was less chemosis and conjunctival injection. The eye was less proptosed and the skin of the lids, which were stretched and tense, lay in loose folds over the receded eye.

\section{Operation}

On May 3, 1968, a right exenteration was performed.

The tumour mass filled the muscle cone and replaced the tissue between the muscle cone and periorbita. The latter stripped with facility off the bony wall which showed no erosion.

The orbit was lined with split-skin graft and kept in position by a mould of cotton-wool impregnated with Acriflavin emulsion. The skin graft was sutured to the cut end of the skin of the orbital margin.

On the tenth post-operative day the orbital pack was removed. The skin graft was in situ and had taken well, apart from a small fistula on the infero-medial wall in relationship to the opening of the nasolacrimal duct.

\section{Histological examination}

The specimen consisted of orbital contents and measured $38 \times 50 \times 43 \mathrm{~mm}$. in the antero-posterior, vertical, and horizontal planes.

A mass infiltrated the extraocular muscles and optic nerve. Vertical section through the tumour showed firm brownish-white tissue with central haemorrhagic and necrotic foci and areas of calcification. The tumour was not well defined and a definitive capsule was not present.

Microscopical examination showed the tumour to be composed of spindle cells, the stroma showing collagen formation in areas. Scanty osteoclast-like giant cells were present in the stroma.

Mitoses were scanty and sarcomatous blood vessels were present. In some areas the spindle-cell stroma appeared quiet and inactive, but elsewhere it was more active.

There was a sudden transition from undifferentiated mesenchymal cells to islands of well differentiated cartilage (Fig. 5), much of which was undergoing calcification.

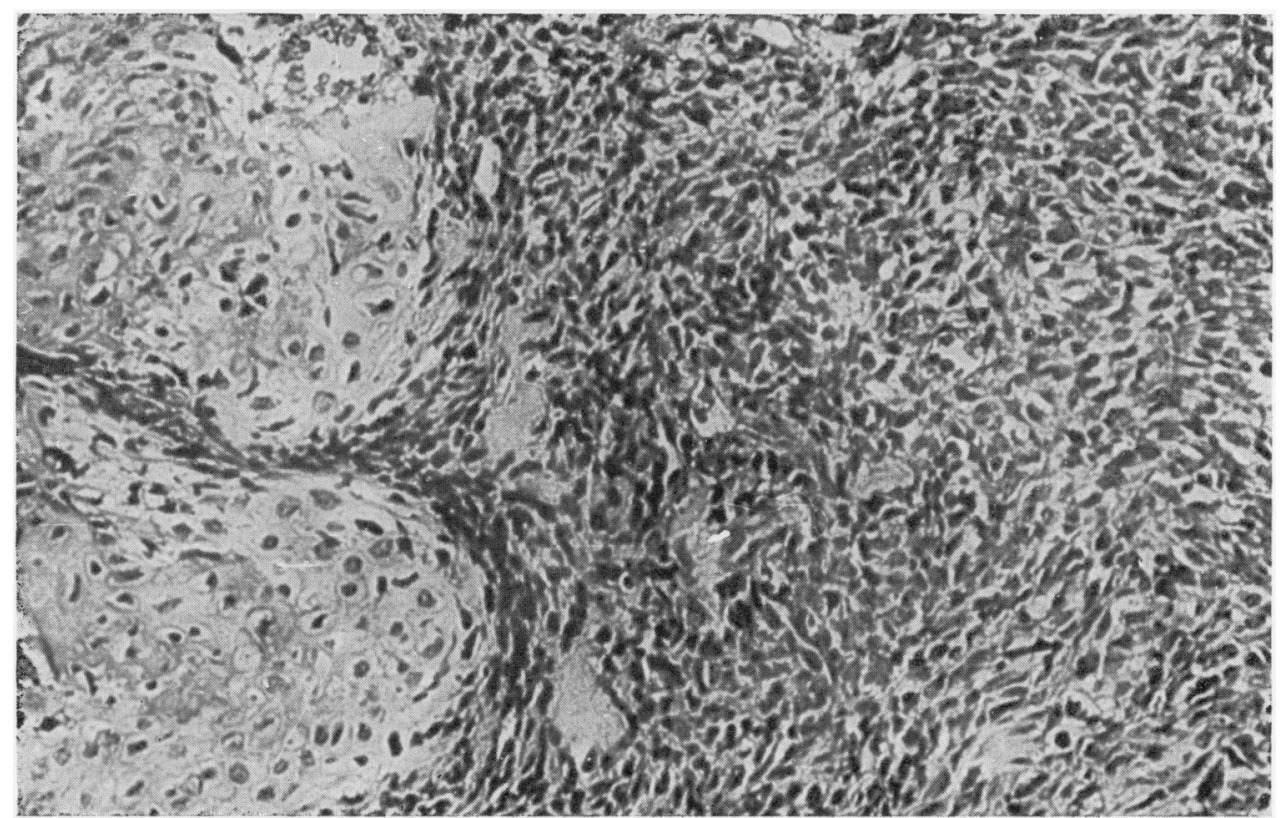

FIG. 5 Mesodermal chondrosarcoma, showing distinct transition from the cellular to the cartilagenous component. Haematoxylin and eosin. $\times 185$ 
In some foci numerous vascular channels were noted (Fig. 6 ) and these channels were surrounded by cells, thus resembling a haemangiopericytoma (Fig. 7).

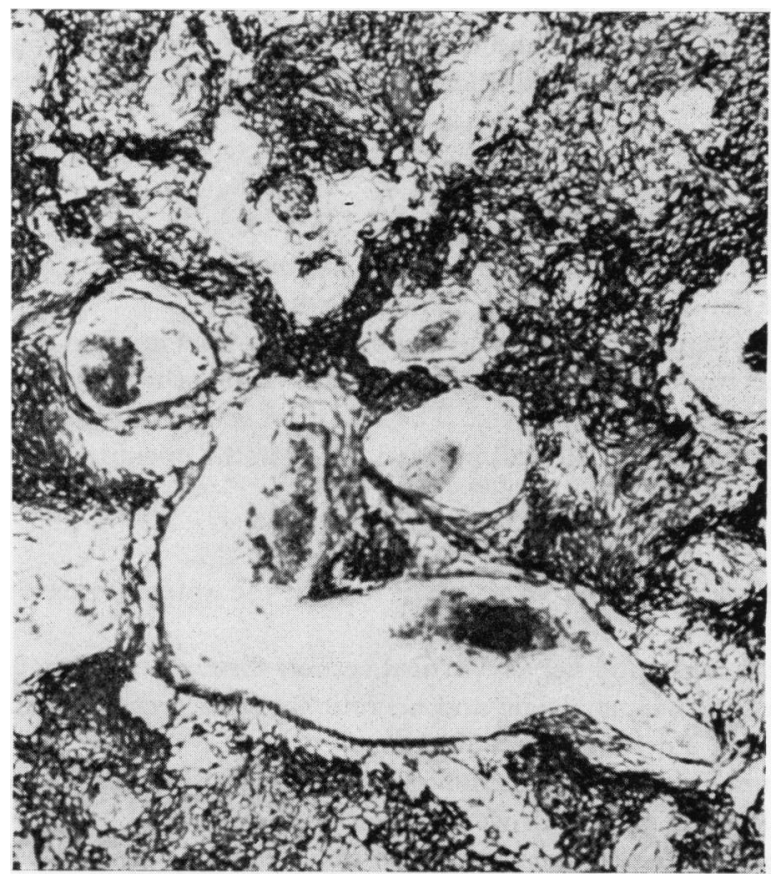

FIG. 6 Mesodermal chondrosarcoma, showing numerous vascular channels. Gordon and Sweet reticulin silver impreg. nation stain. $\times 75$

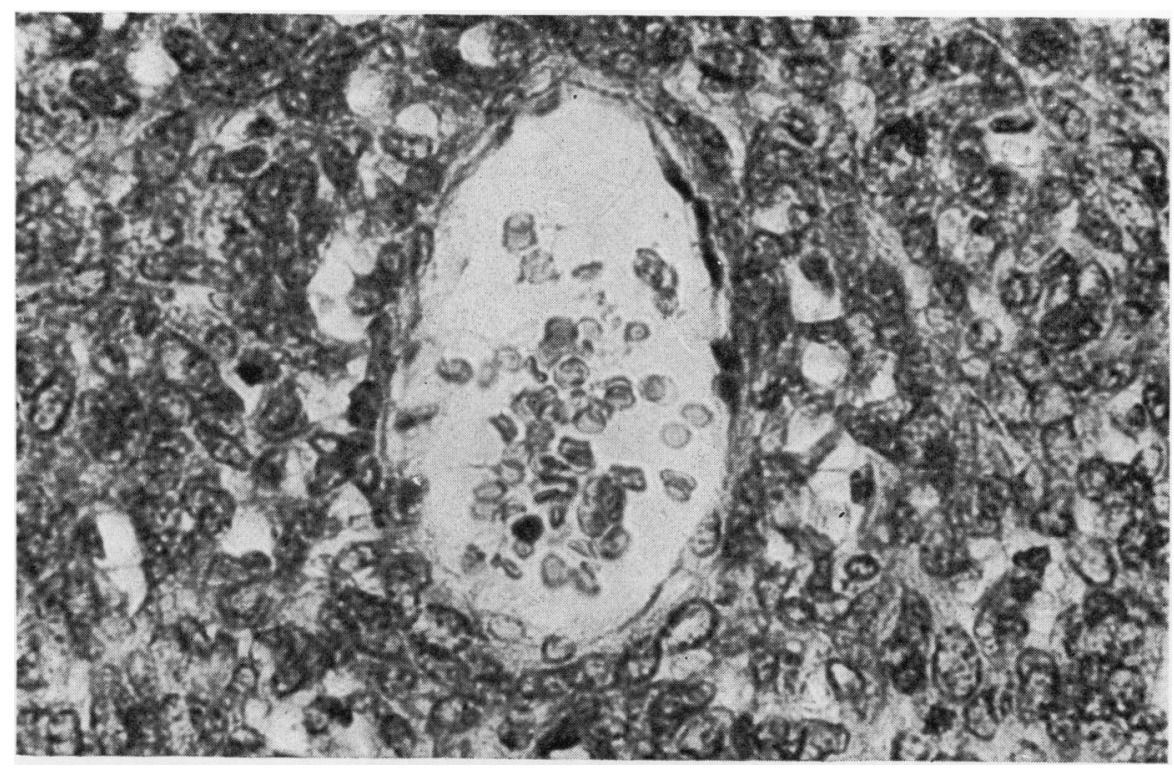

FIG. 7 Mesenchymal cells surround dilated blood channels and resemble a haemangiopericytoma. Haematoxylin and eosin. $\times 300$

The patient was initially assessed at monthly intervals for a year and thereafter at 3-mthly intervals. She was last seen on January 24, 1973, 5 years after the exenteration. There was no evidence of local recurrence or metastases and she was then fitted with a prosthesis. 


\section{Discussion}

Mesenchymal chondrosarcoma is an exceedingly rare tumour of the orbit.

It characteristically occurs in young females ( 19 to 34 years) and presents with proptosis and pain.

Where the follow-up clinical details are known, it has been found that three of the four patients so far described, have survived ro years, 5 years (present case), and 6 months respectively, while one survived 5 years and then died of wide-spread metastases.

The diagnosis is made on the distinctive histological characteristic and not on the clinical findings.

The tumour is composed of rich, cellular, and undifferentiated mesenchymal cells and well-differentiated cartilage. Areas of calcification may occur within the central zone of the cartilage. The mesenchymal cells may occur in sheets and surround vascular spaces and resemble a haemangiopericytoma. The mesenchymal cells may be small, round, or spindle shaped, the nuclei are hyperchromatic and minimal cytoplasm is present.

The treatment in the case described was preoperative deep $x$-ray therapy and cytotoxic agents followed by exenteration. A split-thickness graft was used to line the orbit rather than a temporalis muscle flap, to facilitate examination of the orbit for local recurrence.

Patients should be assessed initially at frequent intervals because of the unpredictability of the tumour.

\section{Summary}

The clinical and histological features as well as the treatment and follow-up of a rare tumour of the orbit, a mesenchymal chondrosarcoma, are described.

This investigation was financed by the Gratitude Fund of Ophthalmology, the Research Fund of the Department of Ophthalmology, University of Cape Town, and the Goosen Trust Fund.

\section{References}

GÁrdenas-ramfrez, L., albores-SaAvedra, J., and de buen, s. (1971) Arch. Ophthal. (Chicago), 86, 4 IO

Guccion, J. G., Font, R. L., Enzinger, F. M., and zimmerman, L. E. (1973) Arch. Path., 95, 336

LiChTENSTEIN, L., and BeRnSTEIN, D. (I959) Cancer (Philad.), I2, I 142

REEH, M.J • (1966) Arch. Ophthal. (Chicago), 75, 82

SAlvador, A. H., Beabout, J. W., and Dahlin, D. C. (1971) Cancer (Philad.), 28, 605

TRZCINSKA-DABROWSKA, Z., WITWICKI, T., and ZIELINSKA, K. (1969) Ophthalmologica (Basel), 157, 24 